\title{
THERMAL ASPECTS OF SELF-CURING POLYMETHYLMETHACRYLATE
}

\author{
C. D. Jefferiss, A. J. C. Lee and R. S. M. Ling, Exeter, Devon, England \\ From the Princess Elizabeth Orthopaedic Hospital, Exeter, and the \\ Department of Engineering Science, University of Exeter
}

\begin{abstract}
Bone necrosis adjacent to self-curing polymethylmethacrylate is a matter of accepted fact. Among the possible causes are mechanical and vascular damage from the preparation of the bone cavity, chemical damage from the monomer and free radicals in the cement dough, and thermal damage from the heat of polymerisation, occurring in this order. Consideration of the tissue reaction to this material, theoretical calculation of the heat output from polymerising acrylic and interface temperature profiles, experimental observations of interface temperatures and maximal temperatures at polymerisation, together with clinical observations, all lead to the view that the bone necrosis is not a consequence of thermal damage, which is unlikely to be a cause of failure of prosthetic fixation. Temperatures recorded from within polymerising acrylic masses are related primarily to the amount of monomer polymerising and are of no clinical significance in the fixation of prostheses. Interface temperatures are related primarily to the surface area of the interface and the thermal characteristics of the cooler material.
\end{abstract}

Since polymethylmethacrylate was first used in orthopaedic surgery there have been many publications criticising its use on the grounds of the damaging effects of the heat produced by polymerisation. Thermal necrosis has been implicated as the main cause of loosening of cemented acetabular cups in total hip replacement (Andersson, Freeman and Swanson 1972) and as a possible cause of the dissolution of the acetabular floor occasionally seen after the same operation (Miller 1972). It has been blamed for burns of the abdomen (Jefferiss 1971). Such statements as: "Polymethylmethacrylate polymerises at 80 degrees Celsius" (Miller 1972) or: "Thermal trauma is substantial at the implant tissue interface" (Homsy, Tullos, Anderson, Differante and King 1972) are not rare. Cooling of prosthetic femoral stems has been recommended (Ohnsorge and Goebel 1970) and other methods involving the use of various types of additives (Homsy et al. 1972) have been considered experimentally.

In the considerable literature, necrosis of bone after the use of cement has often been ascribed to heat, but this is an unproved assumption. The purpose of this paper is to examine the thermal effect of self-curing polymethylmethacrylate in the light of some simple experimental observations on heat evolution from the polymerising resin and some basic aspects of heat transfer theory, together with certain clinical observations. The evidence suggests that necrosis occurring with the normal clinical use of the cement is not caused by heat.

Heat is evolved during the change of the high-energy unstable monomer molecule to the low-energy stable polymer, to the extent that 100 grams of methylmethacrylate monomer produce 13 kilocalories on polymerisa- tion (Meyer, Lautenschlager and Moore 1973; Shadbolt 1973). Thus the amount of heat produced depends upon the amount of monomer polymerising. The temperature reached at any given site depends not only on the amount of heat produced, but also on the rate of its production and the ease with which it can escape. The latter has been given virtually no attention in the orthopaedic literature on this subject. The temperature actually recorded by a thermocouple depends on the precise position of its recording tip in relation to the acrylic mass.

\section{MATERIALS AND METHODS}

Five pairs of cylindrical moulds were made, one of each pair from Teflon and the other from aluminium. The inside diameters of the moulds were $30,20,10,5$ and $2 \cdot 5$ millimetres, and there was a constant ratio of diameter to length of one to three (Fig. 1). A one-millimetre drill hole was bored

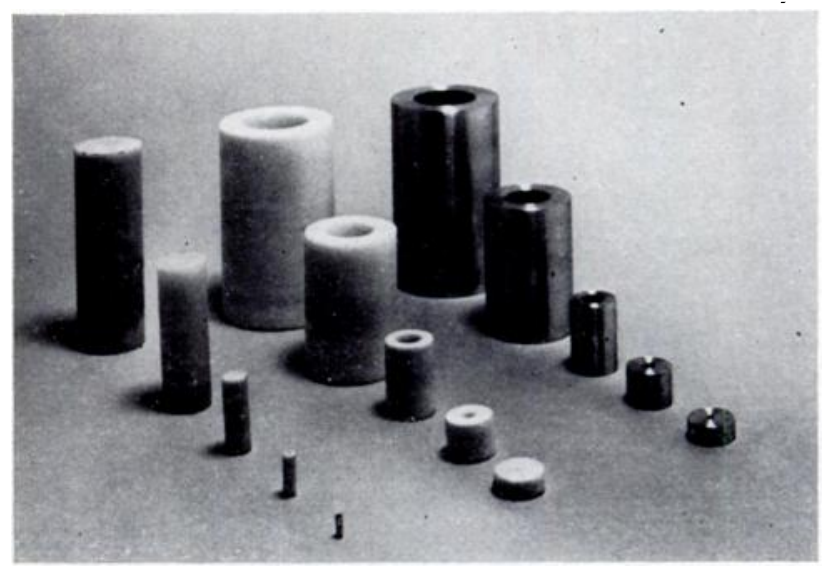

FIG. 1

To show the Teflon and aluminium cylindrical moulds, together with cement specimens.

C. D. Jefferiss, M.B., F.R.C.S., Senior Registrar, Princess Elizabeth Orthopaedic Hospital, Wonford Road, Exeter EX2 4UE, England. A. J. C. Lee, B.Sc., Ph.D., Lecturer in Engineering Science, University of Exeter, Exeter, England.

R. S. M. Ling, F.R.C.S., Consultant Surgeon, Princess Elizabeth Orthopaedic Hospital, Wonford Road, Exeter EX2 4UE, England. 
transversely through the middle of each mould to allow the insertion of a thermocouple. The moulds were then packed with acrylic cement dough, prepared by a standard mixing technique under controlled conditions of temperature (21 degrees Celsius) and a relative humidity of $\mathbf{4 0}$ per cent. The thermocouples were placed with their recording tips in three positions: 1 ) in the middle of the plug; 2 ) on the end surface of the cement plug; and 3 ) on the middle of the side surface of the cement plug at the interface between plug and mould (Fig. 2). Care was taken to ensure that the thermocouples

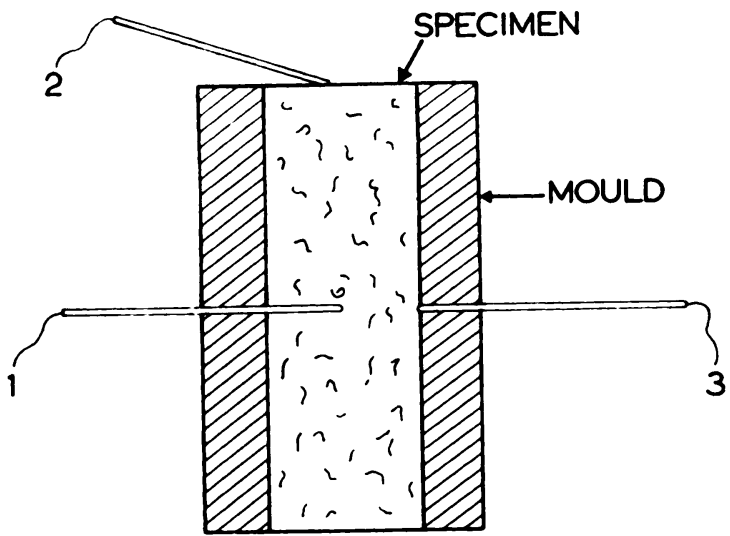

FiG. 2

To show the three positions of the thermocouples in relation to the cement specimens.

on the surfaces of the acrylic were in firm contact with the acrylic dough. The thermocouples were connected to recorders so that the temperature changes before, during and after polymerisation could be followed. The experiments were repeated with the moulds kept in an oven at 37 degrees Celsius, and again with one end of each mould in a waterbath at 37 degrees Celsius.

\section{RESULTS}

The mean peak temperatures reached during polymerisation are recorded in Table I and are depicted graphically in Figure 3.
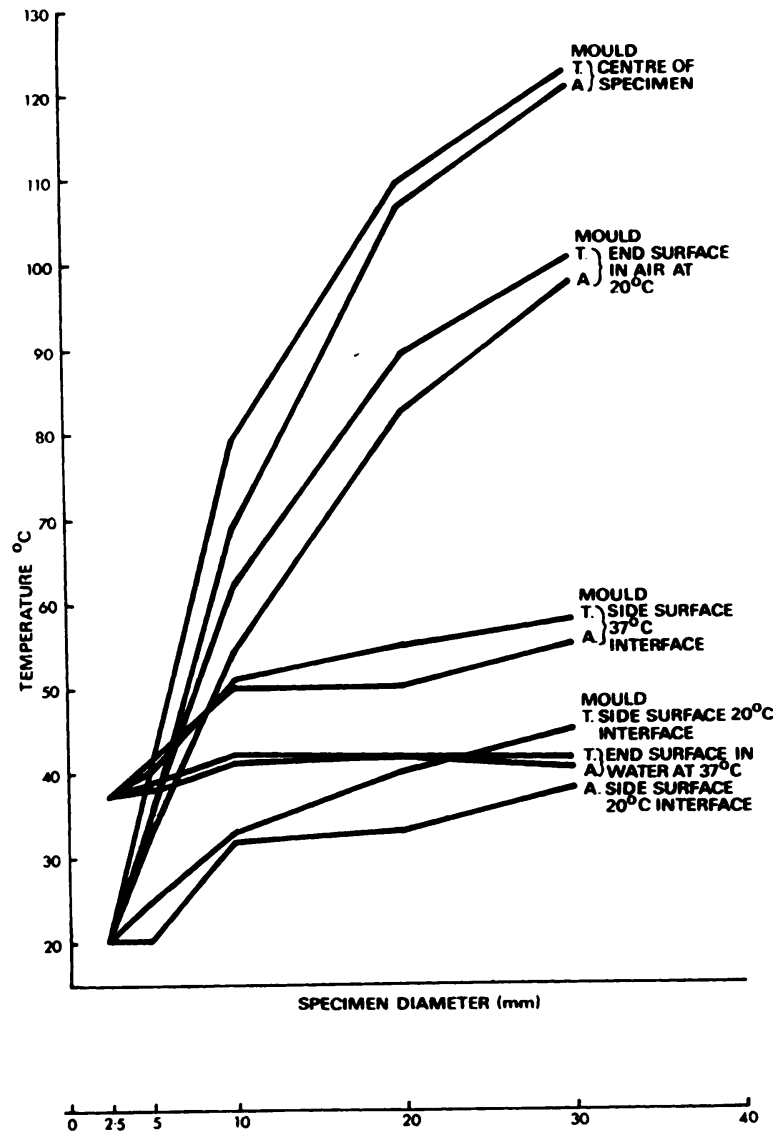

Fig. 3

Mean peak temperatures plotted against specimen diameters.

Theoretical aspects of heat transfer from acrylic cement A theoretical study of the temperature profiles in bone, cement and prosthesis has been made, showing the change in temperature with time after polymerisation. Such a study, employing a three-dimensional system, would be

TABLE I

Peak Temperature at Polymerisation, in Degrees Celsius (Each figure is the mean of three readings)

\begin{tabular}{|c|c|c|c|c|c|}
\hline \multirow[b]{2}{*}{$\begin{array}{l}\text { Cylinder diameter } \\
\text { and material }\end{array}$} & \multirow[b]{2}{*}{$\begin{array}{c}\text { Mean peak } \\
\text { temperature at centre }\end{array}$} & \multicolumn{2}{|c|}{ Mean peak temperature at end surface } & \multicolumn{2}{|c|}{ Mean peak temperature at side surface } \\
\hline & & $\begin{array}{l}\text { Air interphase } \\
\text { at } 20^{\circ} \mathrm{C}\end{array}$ & $\begin{array}{c}\text { Water interphase } \\
\text { at } 37^{\circ} \mathrm{C}\end{array}$ & $20^{\circ}$ interphase & $37^{\circ}$ interphase \\
\hline $30 \mathrm{~mm}$ Tefion & $122 \cdot 25$ & $100 \cdot 5$ & $41 \cdot 3$ & $45 \cdot 0$ & 58 \\
\hline $20 \mathrm{~mm}$ Teflon & $109 \cdot 5$ & $89 \cdot 25$ & $41 \cdot 7$ & $40 \cdot 0$ & 55 \\
\hline $10 \mathrm{~mm}$ Tefion & $79 \cdot 5$ & $62 \cdot 5$ & $41 \cdot 5$ & $33 \cdot 0$ & 51 \\
\hline $5 \mathrm{~mm}$ Teflon & $41 \cdot 5$ & $35 \cdot 7$ & $38 \cdot 0$ & $25 \cdot 0$ & 40 \\
\hline $2.5 \mathrm{~mm}$ Teflon & No detectable rise & No detectable rise & No detectable rise & No detectable rise & No detectable rise \\
\hline $30 \mathrm{~mm}$ Aluminium & $120 \cdot 5$ & $97 \cdot 5$ & $40 \cdot 3$ & $38 \cdot 0$ & 55 \\
\hline $20 \mathrm{~mm}$ Aluminium & $106 \cdot 75$ & $82 \cdot 5$ & $41 \cdot 7$ & $33 \cdot 0$ & 50 \\
\hline $10 \mathrm{~mm}$ Aluminium & $69 \cdot 25$ & $54 \cdot 5$ & $42 \cdot 0$ & $32 \cdot 0$ & 50 \\
\hline $5 \mathrm{~mm}$ Aluminium & 35.0 & $34 \cdot 0$ & $38 \cdot 5$ & No detectable rise & 41 \\
\hline $2.5 \mathrm{~mm}$ Aluminium & No detectable rise & No detectable rise & No detectable rise & No detectable rise & No detectable rise \\
\hline
\end{tabular}


exceedingly complex and unjustified when the accuracy of some of the necessary assumptions is considered. A one-dimensional analysis has therefore been employed, calculating temperatures in "sandwiches" of bone/cement/ steel, and bone/cement/high density polyethylene. Cement temperatures have been chosen arbitrarily as being either 124 degrees or 70 degrees Celsius.

TABLE II

Physical Constants of the Various Substances

\begin{tabular}{|c|c|c|c|c|}
\hline & $\begin{array}{c}\text { Thermal } \\
\text { conductivity k } \\
\mathrm{Cal} / \mathrm{sec} / \mathrm{cm}^{2} /{ }^{\circ} \mathrm{C} / \mathrm{cm}\end{array}$ & $\begin{array}{c}\text { Density } \rho \\
\text { g/ce }\end{array}$ & $\begin{array}{l}\text { Specific } \\
\text { heat } \boldsymbol{C} \rho \\
\mathrm{Cal} / \mathbf{g} / /^{\circ} \mathrm{C}\end{array}$ & $\alpha=\frac{k}{\rho C \rho}$ \\
\hline Bone & $0.0009^{1}$ & $2 \cdot 6^{3}$ & $0 \cdot 162^{4}$ & 0.00214 \\
\hline Bone cement & $0.0004^{1}$ & $1 \cdot 19^{2}$ & $0.35^{2}$ & 0.00096 \\
\hline Steel. & $0.036^{1}$ & $7 \cdot 817^{5}$ & $0 \cdot 118^{5}$ & 0.0391 \\
\hline HDPE & $0.0007^{2}$ & $0.93^{2}$ & $0.53^{2}$ & 0.00142 \\
\hline PTFE & $0.00056^{1}$ & $2 \cdot 2^{2}$ & $0.25^{2}$ & 0.00102 \\
\hline Aluminium. & $0.563^{2}$ & $2 \cdot 7^{5}$ & $0 \cdot 214^{5}$ & 0.9754 \\
\hline Water & $0.0015^{2}$ & 1.0 & $1.00^{2}$ & 0.0015 \\
\hline Air . & $0.000064^{2}$ & $0.0012^{2}$ & $0.24^{2}$ & 0.2222 \\
\hline
\end{tabular}

References: ${ }^{1}$ Meyer et al. (1973); ${ }^{8}$ Kaye and Laby (1959); ${ }^{8}$ Kummer (1972); 'Specific heat of calcium assumed; and ${ }^{6}$ Oberg and Jones (1968).

The assumptions which have been made for the purpose of the analysis are as follows: 1) The cement polymerises instantly and its temperature is therefore assumed to change from ambient to either 70 degrees Celsius or 124 degrees Celsius across its whole width at assumed to be room temperature, taken as 20 degrees. 4) The boundary between the various materials of the "sandwich" is assumed to be smooth and sharp. The various constants employed in the calculations are listed in Table II.

The thermal conductivity of bone is very approximate. No accurate information could be obtained for this material constant, and the figure assumed is a low value as far as bone is concerned, taking no account of blood flow, the presence of fat and differences between cortical and cancellous bone.

\section{Method of calculation}

To calculate interface temperature between the materials, a conservation of energy equation across the boundary was used, together with the heat conduction equation within the materials. This equation may be represented as:$k_{1} \frac{(d t)}{(d x)_{1}}=k_{2} \frac{(d t)}{(d x)_{2}}$ where $k$ is the thermal conductivity, and $d t$ is the temperature change between the interface and a point a short distance $\mathrm{dx}$ into the material. Subscripts (1) and (2) refer to the two materials. Interface temperatures being known, the temperature profiles were computed using a Digital PDP 11 computer and the method of Schmitt (Carslaw and Jaeger 1959), for which a knowledge of the specific heats and of the constant $\alpha$ in Table II was needed.

Temperature profiles are shown in Figures 4 and 5 for cement assumed to polymerise at a temperature of 70 degrees Celsius, and in Figures 6 and 7 for cement assumed to polymerise at 124 degrees Celsius. Even assuming a cement temperature of 124 degrees, it may be noted that the bone temperature does not exceed 71.5 degrees and falls rapidly as the distance from the bone/cement interface increases. Theoretical temperature profiles were also calculated for water/ cement/water, the initial temperatures of the water being taken as $\mathbf{2 0}$ degrees and $\mathbf{3 7}$ degrees Celsius and initial temperatures

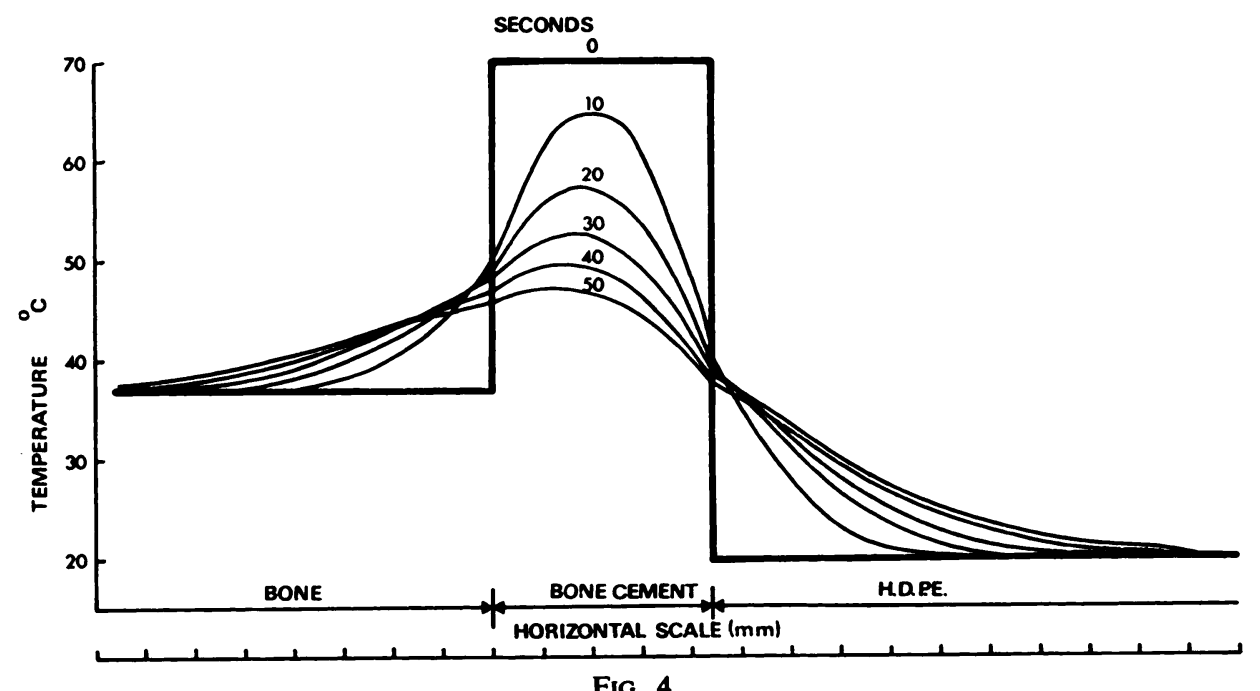

Fig. 4

Theoretical temperature profiles for bone/cement/HDPE, assuming an initial temperature of 70 degrees Celsius.

the instant of polymerisation. 2) The cement temperature is assumed to be uniform at the instant of polymerisation. 3) The initial temperature of bone is assumed to be 37 degrees Celsius and the initial temperature of the prosthesis, whether steel or high density polyethylene, is of the cement being taken as 70 degrees and 124 degrees. Similar profiles were calculated for air/cement, the initial air temperature being 20 degrees and the cement temperatures being taken at 70 degrees and 124 degrees. The air and water were assumed to be still in these calculations because it is extremely difficult to allow for convection currents which in 
fact help in the dissipation of heat. The profiles did demonstrate the insulating effect of air, however, which explains the often observed fact that a thin layer of blood on the surface of polymerising acrylic may show gross evidence of temperature change when its opposite surface (i.e., away from the acrylic) is exposed to air, because heat easily transferred from in the middle of the cement mass requires a thickness of three centimetres, while a temperature of 70 degrees needs a thickness of one centimetre. Such masses of cement are rarely employed clinically. Temperatures at the interface between the cement and its surroundings are always

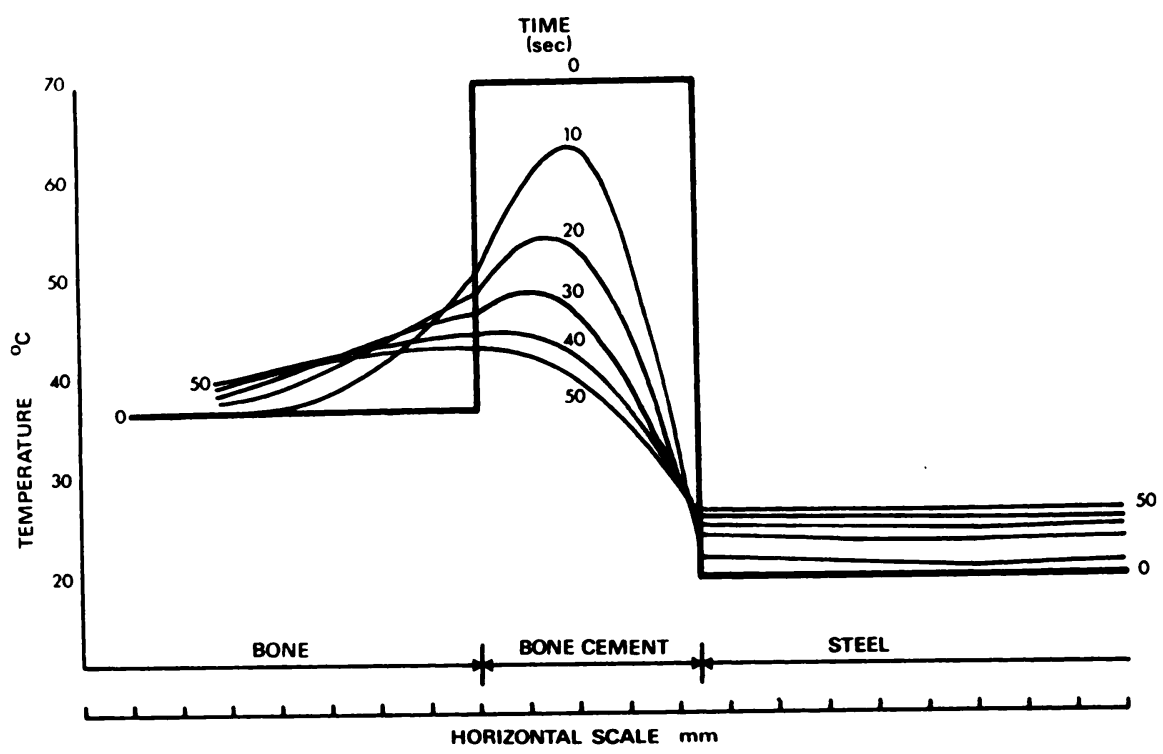

Fig. 5

Theoretical temperature profiles for bone/cement/steel, assuming an initial temperature of 70 degrees Celsius.

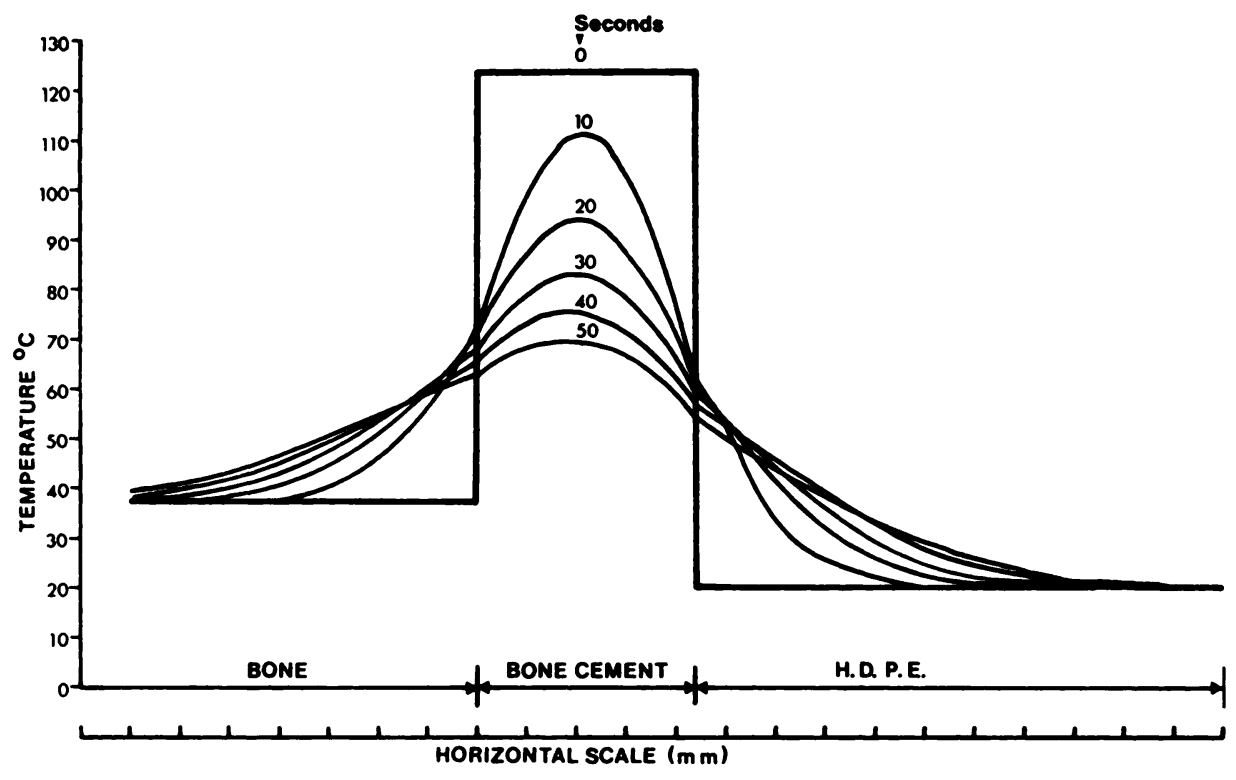

Fig. 6

Theoretical temperature profiles for bone/cement/HDPE, assuming an initial temperature of 124 degrees Celsius.

the acrylic into the blood cannot be lost easily at the blood/air interface.

There are numerous considerations suggesting that temperatures derived in this analysis are higher than those achieved clinically. 1) In vivo, the cement does not polymerise instantaneously and the temperature rise is gradual, at least initially. 2) Reference to Table I indicates that to achieve a temperature of 124 degrees Celsius even appreciably lower than in the middle of the mass, depending upon the thermal characteristics and the initial temperature of the surrounding material. The assumed initial temperatures of the cement in this study are therefore unrealistically high. 3) The thermal conductivity assumed for bone is likely to be lower than the true figure. 4) The cement/bone interface is not smooth and sharp in vivo, especially where the bone is cancellous. 


\section{DISCUSSION}

The amount of monomer polymerising-Monomer makes up approximately one-third of the mass of the acrylic dough. The exact amount depends upon the brand of acrylic and to a lesser extent on the method and duration of mixing (Lee, Ling and Wrighton 1973). The amount area through which the transfer takes place. The latter is very important clinically, the difference between cortical and cancellous bone being substantial in this respect. The figures in columns 3, 4, 5 and 6 of Table I emphasise the great significance of the thermal characteristics of the material in contact with the acrylic mass. This factor is entirely ignored in thermovision estimates of cement

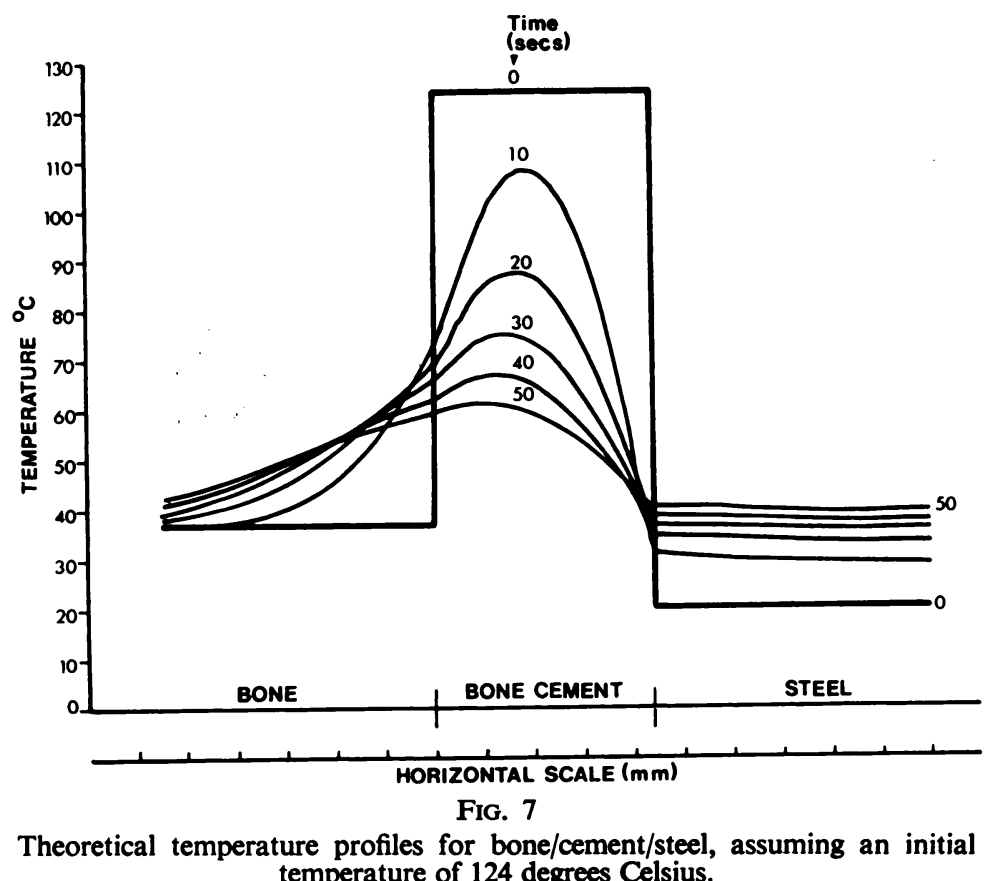

of monomer is therefore proportional to the amount of acrylic dough. Consideration of Table I and Figure 1 makes it clear that the peak temperatures in the centre of the cement masses are related primarily to their size. Temperatures of 120 degrees were regularly reached in the middle of the cylinder measuring 30 by 90 millimetres. As the cylinders became smaller, so the peak temperatures became less; and the temperature was always lower when the mould was made of aluminium rather than Teflon, owing to their relative thermal characteristics. In the smallest cylinders, 2.5 millimetres in diameter, the heat evolved on polymerisation was not sufficient to produce a detectable rise in temperature. The highest temperatures recorded at the surfaces of the acrylic were conditioned not so much by the mass of the acrylic itself as by the thermal characteristics and starting temperature of the material in contact with it. This is important when considering the clinical use of the material.

Ease of dispersal of heat-The acrylic mass itself is a relatively poor conductor and therefore heat escapes less easily from the centre. Escape from the surfaces is governed essentially by the processes of conduction, convection and radiation, though in the body only the first is of significance. The rate of heat transfer from one system to another is proportional to the temperature gradient at the interface between the systems, the thermal conductivities of the materials involved and the surface temperature (Hupfauer and Ulatowski 1972). Thermal conductivity controls mainly the temperature gradient at the interface, whereas the temperature itself is inversely related to the product of the density and the specific heat of the cooler material at the interface.

Position of the recording thermocouple-The position of the recording tip of the thermocouple in relation to the acrylic mass influences the temperature recorded. This was demonstrated by Meyer and his colleagues (1973) and is emphasised by the theoretical treatment above.

Consideration of these factors in relation to the in vivo circumstances and the cement/bone junction-The cement/ bone junction is often referred to as though it were the site of a sudden transition from bone to cement. This may be the case with relatively smooth cortical bone, but it is not so with the rough, irregular, porous surface of cancellous bone. Charnley (1970a) has emphasised the importance of adequate extrusion of cement into cancellous bone spaces in procuring a satisfactory bond, and has pointed out the three-dimensional relationship of bone trabeculae to the cement when this is achieved. In these circumstances the cement/bone junction is wide, the cement having been forced through the intertrabecular spaces while in the viscous state. On the cement side of the junction is pure cement and on the bone side is cancellous bone with varying proportions of each between the two (Fig. 8). These circumstances have important 
implications with regard both to the amount of heat produced and to its dispersal.

The production and dispersal of heat at the cement/bone junction-The irregularity of the cement surfaces in the body when cancellous bone has received the cement are well shown in Figure 9. At the time of cement insertion

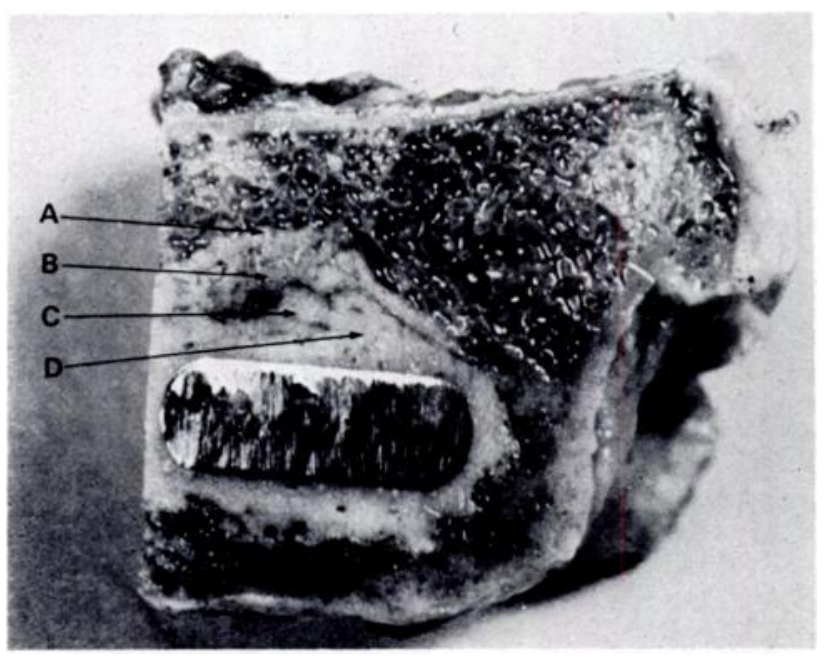

FiG. 8

A photograph of a transverse section cut through femur, cement and prosthetic stem. The specimen was obtained from a patient who died from a ruptured aortic aneurysm two weeks after total replacement of the hip. Thermocouple tips placed at A, B, C or D would record different maximum temperatures during polymerisation of the cement.

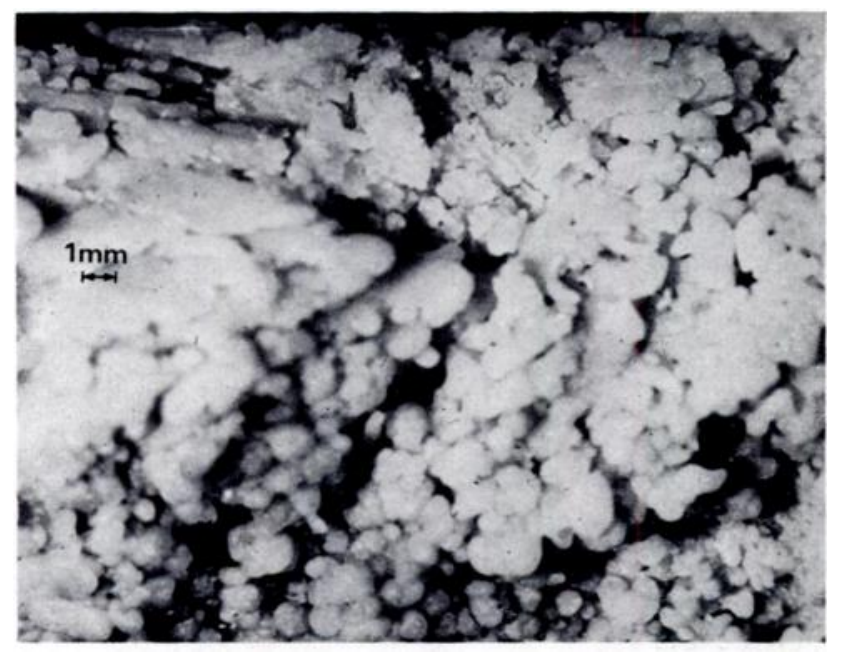

FIG. 9

To show the cement surface round a prosthetic femoral stem after the bone had been dissolved away. The millimetre scale demonstrates the size of the cement asperities.

and extrusion the gaps between the cement projections were filled with bone trabeculae that resisted the flow of dough. These trabeculae had been removed in the preparation of the specimen. A millimetre scale incorporated in Figure 9 demonstrates the size of the cement asperities. They are small. Some idea of heat production from acrylic masses of this order can be gained from the following simple calculation.
One hundred grams of monomer produces 13,000 calories on polymerisation. One whole cement mix ( 60 grams of dough) contains approximately 20 grams of monomer. The polymerisation of 60 grams of dough therefore produces 2,600 calories. One gram of dough therefore produces on polymerisation 43.3 calories. The density of the polymerised dough is approximately 1.0. Reference to Figure 9 suggests that many of the asperities on the surface of the cement are smaller than 3 by 2 by 2 millimetres; thus their volume is less than 15 cubic millimetres. This volume of dough on polymerisation produces 0.65 calorie.

When the surface against which the acrylic polymerises is smooth, for example cortical bone, these small projections of acrylic are not formed, and consequently the acrylic mass in direct contact with bone has a relatively smaller surface area than when extruded into cancellous bone, with obvious implications for the production and dispersal of heat. The large area of a surface such as that shown in Figure 9 provides a more favourable situation for the dispersal of heat than a smooth surface of acrylic in contact with cortical bone. In addition, there may be differences in the thermal characteristics of cancellous and cortical bone. The porous nature of cancellous bone, its richer blood supply, and the presence of intertrabecular fat suggests that its thermal conductivity and thermal capacity may be higher than those of cortical bone.

Position of the thermocouple-Reference to Figure 8 emphasises the importance of thermocouple positioning when attempts are made to record cement/bone interface temperatures during surgical procedures. Bone trabeculae are clearly visible well within the outermost portion of acrylic. It is clear that thermocouple tips placed at the points marked $\mathrm{A}, \mathrm{B}, \mathrm{C}, \mathrm{D}$ will record different maximum temperatures at polymerisation of the acrylic, at $A$ the lowest and at D the highest. This sort of consideration, emphasised in the theoretical treatment above, may explain the very different figures quoted in the literature for the highest temperatures recorded at the cement/bone junction in the body. A difference of as little as a millimetre in the position of the thermocouple tip can produce a highly significant change in the temperature recorded, and accurate placement of the recording tip in vivo is extremely difficult.

Thermal necrosis-Most authors have commented on the presence of dead tissue adjacent to implanted acrylic cement, and generally the necrosis has been ascribed to the presence of the acrylic per se, being produced either by chemical or thermal trauma. The fact that it occurs in tissue culture adjacent to acrylic dough may be thought to lend support to this view (Hulliger 1962).

In clinical practice, when acrylic cement is used for skeletal fixation to bone, two other factors may influence the tissue reaction: first, the effect of the preparation of the bone cavity for the reception of the acrylic dough; and second, the method and site of insertion of the dough. These help to explain the great reported variations in the histological response to implanted acrylic.

Collins (1953) has shown how a relatively mild 
manoeuvre such as driving a triflanged nail up the neck of the femur produces shattering of the trabeculae with local extravasation of blood up to 4 millimetres from the surface of the nail, and death at the extremities of the trabeculae adjacent to the nail to a depth of 0.2 to 0.3 millimetre. Rhinelander (1972) and his colleagues pointed out the vascular consequence of reaming the medullary canal of the femur in dogs and demonstrated subsequent death of the inner layers of the cortex. The histological appearances adjacent to implanted acrylic in the experiments on rabbits of Scales, Duff-Barclay and Burrows appearances surrounding the implant differed from those found by Charnley.

Theoretically, damage to bone in operations in which acrylic cement is used may be considered as mechanical, vascular, chemical and thermal, taking place in that order.

It would be difficult to imagine a more violent assault on endosteal bone than that occasioned by the preparation of the medullary canal of the femur for the reception of a prosthesis or acrylic cement. In view of the work of Collins (1953) and of Rhinelander and his

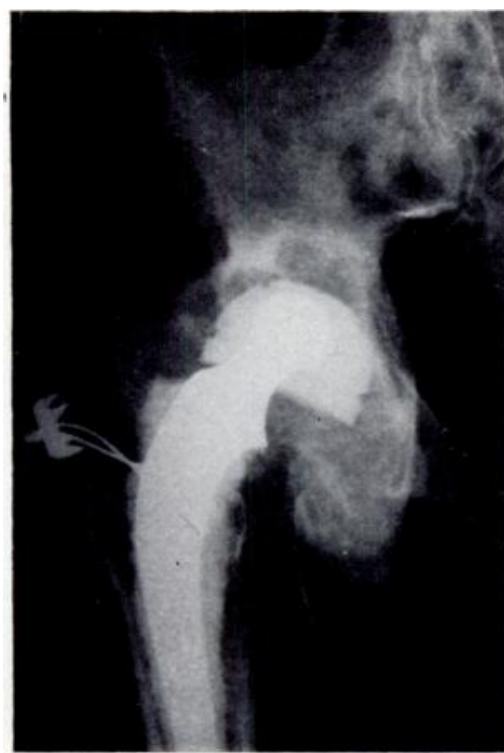

FIG. 10

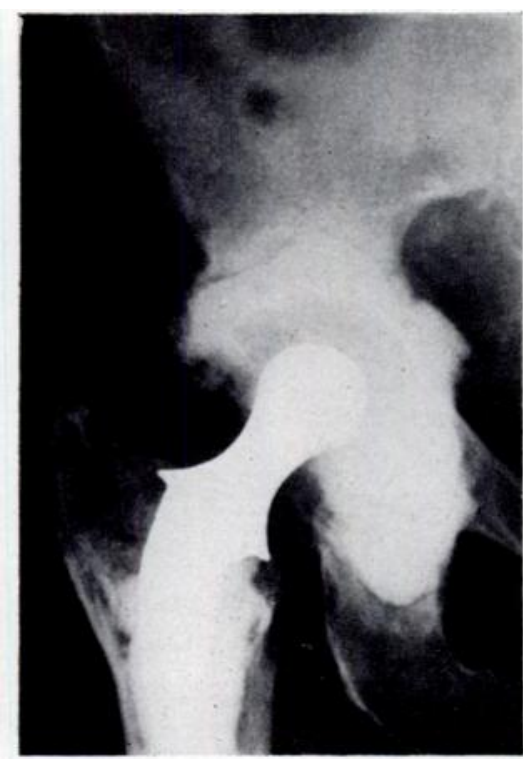

FiG. 11

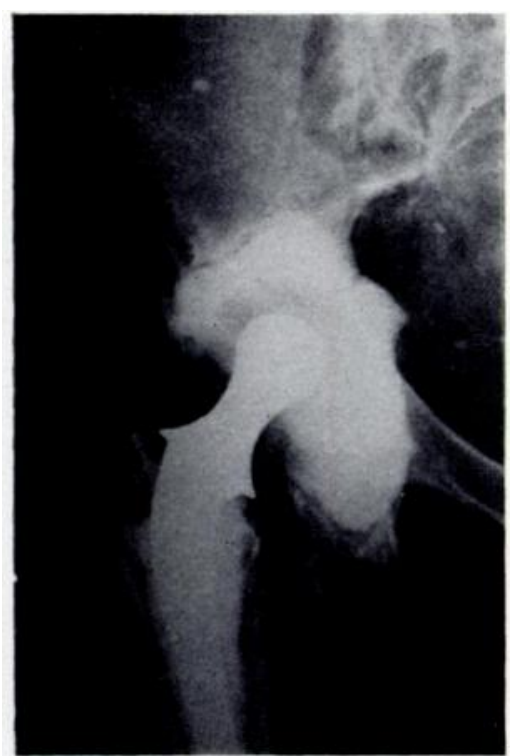

Fig. 12

Figure 10-A radiograph showing a worn Teflon cup. Figure 11-The same case showing replacement with a new cup of high density polyethylene, with a large amount of acrylic being employed for fixation. Figure 12-The same case showing satisfactory appearances six years after revision.

(1965) were attributed to acrylic, but could equally well have been due to the vascular effect of reaming before insertion of the cement. Homsy et al. (1972) reported the development, in dogs, of fibrous tissue sequestration membranes of thickness up to 3 millimetres surrounding the acrylic implant. This contrasts with the findings reported by Charnley $(1970 b)$ in man, where such thick membranes were conspicuous by their absence. In interpreting his material, Charnley emphasised the importance of the prior knowledge that the clinical results had been excellent in patients under study. This implies sound prosthetic fixation, and the technique of implantation included a deliberate attempt to achieve forcible extrusion of the cement dough into trabecular bone. Homsy's (1972) sections at one hour after implantation, the description of the method of implantation and the fact that it was possible to move the implant in relation to its bed (Homsy 1969), make it clear that similar forcible extrusion of the acrylic dough into cancellous trabecular spaces had not been achieved in the circumstances of his experiments. It is therefore not surprising that fixation was inadequate and that the histological colleagues (1972), it is naive to assume that the cells at the surface of the raped bone are undamaged by this manoeuvre.

The insertion of acrylic dough brings into contact with bone a powerful fat solvent; monomer and fat are freely miscible (Shadbolt 1973). Moreover, the cement dough contains free radicals (not present in monomer itself, or in the polymer, but generated during the activation reaction) that are chemically highly reactive. Chemical damage to lipids is certain, including lipid constituents of cell walls, and the free radicals are likely to produce protein coagulation. Ohnsorge and Holm (1970) used scanning electron-microscopy to produce evidence that protein coagulation does take place adjacent to acrylic cement. Chemical damage is thus superimposed on the pre-existing mechanical and vascular damage. This continues until polymerisation, at which point the temperature rises. Any thermal effects must therefore follow those due to mechanical, vascular and chemical trauma. Temperatures above 45 degrees Celsius may produce denaturation of young uncrossed linked collagen molecules, but permanent molecular rearrangement does 
not occur unless such temperatures are maintained for an hour or more. Irreversible contraction of isolated collagen fibres takes place at temperatures of 60 to 65 degrees Celsius (Hall 1974), but in bone, of course, the collagen is protected to a considerable extent by the calcified elements.

The theoretical and experimental work reported in this paper suggests that in vivo such temperatures are rarely achieved at the cement/bone interface, particularly where cancellous bone is involved, and certainly are not maintained for more than very short periods. It is therefore reasonable to conclude that bone necrosis adjacent to clinically implanted polymethylmethacrylate is a result of mechanical, vascular and chemical factors rather than of thermal origin.

It is clear that the highest temperatures at the cement/ bone interface will be achieved in those cases in which the largest amounts of acrylic are used, especially in combination with a plastic prosthetic component. If thermal damage were to occur at all in vivo, it should occur in this type of case. If thermal damage does occur, and if it is a contributory factor to mechanical failure of fixation, the latter should be seen commonly in cases in which very large masses of acrylic are used.

The series of 168 total replacements with Teflon cups subsequently revised at the Centre for Hip Surgery (Charnley 1973) is relevant in this connection. After the cups and the damaging granulomata had been removed, large acetabular cavities were produced which frequently required a double mix of cement to procure fixation for a new cup made of high density polyethylene. Figures 10 to 12 demonstrate the large masses of acrylic used. Between four and seven and a half years later thirteen of these 168 cases failed, half from sepsis and half from mechanical failure. A mechanical failure rate of six out of 168 in these difficult circumstances must be considered low; it does not support the view that thermal damage was to blame.

The authors acknowledge with gratitude help from Mr H. Jackson Burrows, Dr Mary Catto, Professor John Charnley, Dr David A. Hall and Dr Henry Zienkiewicz. North Hill Plastics generously supplied the acrylic cement used in the experiments.

\section{REFERENCES}

Andersson, G. B. J., Freeman, M. A. R., and Swanson, S. A. V. (1972) Loosening of the cemented acetabular cup in total hip replacement Journal of Bone and Joint Surgery, 54-B, 590-599.

Carstaw, H. S., and Jaeger, J. C. (1959) Conduction of Heat in Solids. Second edition. Oxford: The University Press.

Charnley, J. (1970a) Acrylic Cement in Orthopaedic Surgery. Edinburgh and London: E. and S. Livingstone Ltd.

Charnley, J. (1970b) The reaction of bone to self-curing acrylic cement. Journal of Bone and Joint Surgery, 52-B, 340-353.

Charnley, J. (1973) Personal communication.

Collins, D. H. (1953) Structural changes around nails and screws in human bones. Journal of Pathology and Bacteriology, 65, 109-121.

Hall, D. A. (1974) Personal communication.

Homsy, C. A. (1969) Prosthesis seating compounds of rapid cure acrylic polymer. Paper read at the Joint Workshop on Total Hip Replacement and Skeletal Attachment. National Academy of Sciences and American Academy of Orthopaedic Surgeons.

Homsy, C. A., Tullos, H. S., Anderson, M. S., Differante, N. M., and King, J. W. (1972) Some physiological aspects of prosthesis stabilization with acrylic polymer. Clinical Orthopaedics and Related Research, 83, 317-328.

Hulliger, L. (1962) Untersuchungen über die Wirkung von Kunstharzen (Palacos und Ostamer) Gewebkulturen. Archiv für orthopädische und Unfall-Chirurgie, 54, 581-588.

Hupfauer, W., and Ulatowski, L. (1972) Die Temperaturentwicklung verschiedener Knochenzemente während des Abhärtungavorganges. Archiv für orthopädische und Unfall-Chirurgie, 72, 174-184.

Jefferiss, C. D. (1971) Avoidable complications of McKee-Farrar arthroplasty. British Medical Journal, $2,382$.

Kaye, G. W. C., and Laby, T. H. (1959) Tables of Physical and Chemical Constants and some Mathematical Functions. Twelfth edition. London: Longman.

Kummer, B. K. F. (1972) Biomechanics of bone. In Biomechanics, its Foundation and Objectives. Edited by Y. C. Fung, N. Perrone and M. Auliker. Englewood Cliffe, N.J.: Prentice-Hall.

Lee, A. J. C., Ling, R. S. M., and Wrighton, J. D. (1973) Some properties of polymethylmethacrylate with reference to its use in orthopaedic surgery. Clinical Orthopaedics and Related Research, 95, 281-287.

Meyer, P. R., Jun., Lautenschlager, E. P., and Moore, B. K. (1973) On the setting properties of acrylic bone cement. Journal of Bone and Joint Surgery, 55-A, 149-156.

Miller, A. J. (1972) Late fracture of the acetabulum after total hip replacement. Journal of Bone and Joint Surgery, 54-B, 600-606.

Oberg, E., and Jones, F. D. (1968) Machinery's Handbook. Eighteenth edition. Edited by H. L. Horton and P. B. Schubert. Brighton: Machinery Publishing Co. Ltd.

Ohnsorge, J., and Goebel, G. (1970) Die Verwendung Unterkülter Metallendoprosthesen in der Hüftchirurgie. Zeitschrift für Orthopädie und ihre Grenzgebeite, 107, 683-696.

Ohnsorge, J., and Holm, R. (1970) Änderungen der Spongiosafeinstruktur unter dem Einfluss des auspolymerisierenden Knochenzementes. Zeitschrift für Orthopädie und ihre Grenzgebeite, 107, 405-411.

Rhinelander, F. W. (1972) Circulation in bone. In The Biochemistry and Physiology of Bone. Second edition. Volume 2, Chapter 1, pp. 2-77. Edited by G. Bourne. New York and London: Academic Press.

Scales, J. T., Duff-Barclay, I., and Burrows, H. J. (1965) Some engineering and medical problems associated with massive bone replacement. In Biomechanics and Related Bio-Engineering Topics, pp. 205-239. Edited by R. M. Kenedi. Oxford: Pergamon.

Shadbolt, L. E. (1973) Personal communication. 